\title{
Swedish Stock Recommendations: Information Content or Price Pressure?
}

\author{
Erik R. Lidén \\ Göteborg University, Sweden
}

The paper analyzes stock-price reactions to stock recommendations published in printed Swedish media and also trading volumes at and around the publication day, bid/ask spreads, and the post publication drift in recommended stocks for the period 1995 - 2000. Its small size and limited number of actors makes the Swedish stock market an interesting comparison to the U.S. stock markets. The positive publication-day effect for buy recommendations was almost fully reversed after 20 days, supporting the price pressure hypothesis, and the effect for sell recommendations was negative and prices continued to drift down, supporting the information hypothesis. Analysts seem to hand their information to clients before publication, whereas no such information leaking pattern was observed for journalists. The impact to recommendations from journalists was significantly larger than analyst recommendations, implying a tradeoff between the size of pre-publication cumulative abnormal returns and the publication-day effect (JEL: G10, G14, G20).

Keywords: price pressure hypothesis, information hypothesis, journalists, analysts.

\section{Introduction}

The buy and sell recommendations of stocks published in newspapers and business magazines are based on analysts' and journalists' interpretations of information they possess, hence they are second-hand information. In an efficient market, recommendations containing new "relevant" information should lead to a price reaction exclusively on the publication day $(P D)$. Previous literature has proposed two different hypotheses regarding observed abnormal returns $(A R S)$ on and about the $P D$. The price pressure hypothesis $(P P H)$ suggests that the recommendations

* The author gratefully acknowledges comments on this paper received from participants in the 2002 FMA Doctoral Tutorial in Copenhagen, Denmark. The following also deserve thanks for helpful comments: Brad Barber, Marcus Eliason, Sorin Maruster, Eugene Nivorozhkin, Henrik Röhs, Boo Sjöö, Richard Sweeney, Clas Wihlborg, and four anonymous referees. I am thankful for financial support received from Bankforskningsinstitutet. The usual disclaimer applies.

(Multinational Finance Journal, 2007, vol. 11, no. 3/4, pp. 253-285)

(C) Multinational Finance Society, a nonprofit corporation. All rights reserved.

DOI: $10.17578 / 11-3 / 4-4$ 
create temporary buying or selling pressure from naive investors who cause the abnormal returns trying to profit from them. The information hypothesis $(I H)$ suggests that the recommendations reveal relevant (and potentially profitable) information, which creates fundamental revaluation of stock prices upon arrival on the financial markets. Using data on stock recommendations in Swedish printed media, I discuss whether observed $A R S$ on the $P D$ have a temporary (supporting $P P H$ ) or permanent effect (supporting $I H$ ). Previous literature on stock recommendations in newspapers and business magazines have focused on the U.S. stock markets, and mainly on recommendations presented in the Wall Street Journal and Business Week. Exploiting the reaction to recommendations published in printed media outside the U.S. will thus contribute to a more complete picture. A summary of all the referenced studies on stock recommendations in newspapers and business magazines is presented in table $\mathrm{A}$ in the appendix.

Compared to the U.S. stock markets, the Swedish stock market consists of a small number of firms with large market capitalization, and a large number of firms with relatively low market capitalization. More importantly, there are fewer active journalists and analysts on the Swedish market, thus lower competition between those analyzing stocks. Examining stock recommendations from the G7 countries (i.e., Canada, France, Germany, Great Britain, Italy, Japan, and United States), Jegadeesh and Kim (2003) show that the lower the competition between those analyzing the market, the more difficult it gets uncovering mispriced stocks, something supported by two previous studies on stock recommendations published in different Turkish magazines. Analyzing the recommendations published in the column "Investor Ali" of Moneymatik magazine during the period 1993 - 1998, Muradoglu and Yazici (2002) found that a small investor acting on the recommendations would not earn statistically significant $A R S$. However, "preferred investors" could earn ARS on this information prior to publication. The evidence in Kiymaz (2002), which studied the "gossip" published in Ekonomik Trend weekly during the period 1996 - 1997, presented similar results. Although both of these studies were based on a limited number of observations and focused exclusively on buy recommendations, they suggest that published recommendations in stock markets with less competition among journalists and analysts provide less value to small investors.

The main contribution of this paper to the existing literature is testing whether stock prices react to published stock buy and sell 
recommendations in various Swedish printed media during the period $1995-2000$ and whether there are differences in the recommendations published by journalists to analysts. To my knowledge, this has not been done in previous research. It is also discussed whether found stock-price reactions at the publication day was due to information content or pricepressure. Because of the substantial as well as potentially important differences in the job description between journalists and analysts, analyzing the differences in recommendation behavior is an important issue since analysts have clear incentives to publish stock recommendations in the newspapers or business magazines. Analysts may therefore use printed media as an outlet for second-hand recommendations, i.e., there is a potential bias to be expected from their recommendations. If this is found to be the case, editors of the newspapers and business magazines publishing stock recommendations should ask themselves whether or not to publish recommendations in the best interest of their readers or in the best financial interest of a limited number of analysts and their clients.

The results in this paper show that buy recommendations results in a statistically significant positive $P D$ effect. At the publication day, a decreasing bid/ask spread and an increased trading volume was documented, clear evidence of price pressure. The documented reversion in stock prices following these recommendations also supports the price pressure hypothesis. Sell recommendations result in a statistically significant negative $P D$ effect, followed by an increased bid/ask spread, indicating that the market maker faced informed traders. During the following six-month period, stock prices continued to decrease, thus supporting the information hypothesis. Previous research has failed to come up with an explanation to why buy recommendations generally support the $P P H$ while sell recommendations generally support the $I H$. We believe that this may be due to structural differences in buy to sell recommendations. Publishing favorable recommendations, the newspaper or business magazine probably sell more single copies. Because of their positive nature, these recommendations can be given with less background information. Sell recommendations are more sudden to its nature, probably demands more of investigative work, and since a source to mispricing has been found, they create further confusion regarding the "true" value of the stock on the markets. These structural differences may explain the found asymmetry.

Also, journalist recommendations had greater impact than did those of analysts, a finding in line with previous research. I show that this is 
mainly due to analysts handing their information to clients prior to publication, which is also supported by higher than normal trading volumes prior to publication. Analysts' clients consequently get value for fees paid, leaving no further value for those informed later. Another interesting finding is that the larger the effect during the pre-publication period was, the lower was the $P D$ effect. Finally, the most positive buy recommendations were published during weekdays, and the most negative sell recommendations were published during weekends.

The remainder of this paper is organized as follows. Section II describes the tested hypotheses, Section III discusses the data, while Section IV explains the methods used. The results are presented in Section V, while Section VI summarizes and draws conclusions.

\section{Hypotheses}

Assuming that the Swedish stock market is (at least) semi-strong efficient, we expect the recommendations to have an effect on stock prices at the $P D$ only. In fact, most of the previous research indicates that buy recommendations result in a statistically significant positive $P D$ effect, while a discernible negative $P D$ effect is observed for sell recommendations; hence stock prices react to published recommendations. ${ }^{1}$ If drifts from the stock-price levels on the $P D$ are observed on average in the short run, this gives support to either the $P P H$, or the $I H$. For example, if we observe a positive publication day effect to buy recommendations followed by an increase in prices, this indicates that those recommendations had information content. The described pattern would violate the Efficient Market Hypothesis, which states that an investor should not be able to consistently profit from following this information. The majority of studies also support the notion that investors overreact to buy recommendations, thus supporting the $P P H .^{2}$ Furthermore, investors tend to under react to sell recommendations in the short term, thus supporting the $I H .^{3}$ This leads us to our first hypothesis.

1. See Canes and Lloyd-Davies (1978), Liu et al. (1990), and Barber and Loeffler (1993).

2. See Canes and Lloyd-Davies (1978), Liu et al. (1990), Barber and Loeffler (1993), Mathur and Waheed (1995), and Liang (1999).

3. See Liu et al. (1990), Palmon et al. (1994), Sant and Zaman (1996); who all report statistically insignificant but negative cumulative abnormal returns from the day following the $P D$ to the end of the event window. 
Hypothesis I: If the recommendations contain new information, stock prices should react to this information exclusively on the publication day.

A few words on the differences between journalists and analysts in publishing stock recommendations. In society, journalists and analysts act as information intermediaries. ${ }^{4}$ They sell information to the public, who find it too costly to gather the information themselves. Journalists are usually employed by a specific newspaper or business magazine, and analysts are employed by a bank or a brokerage firm. The information journalists possess is sold via the newspaper or business magazine they write for. The information analysts possess is sold primarily to private clients, and secondarily releasing it (free of charge) to the public via printed or broadcasted media. Furthermore, analysts work in general exclusively with a set of companies which they cover, whereas journalists cover a much larger spectrum of companies. As a consequence of the above, journalists are expected to publish articles, whereas recommendations from analysts are voluntary. Since analysts have incentives to give either a favorable or an unfavorable recommendation from which they themselves or their clients can profit, we can expect these recommendations to be second-hand. These differences in job description between journalists and analysts leads to differences in expected recommendation behavior between the groups:

Hypothesis II: The profitable information in analyst recommendations, irrespective of its kind, will be taken advantage of well before publication.

If the profitable information contained in analyst recommendations have been taken advantage of prior to its publication, the impact should be lower on the $P D$ compared to recommendations from journalists. This can be expected since the information is known to some actors on the marketplace, and therefore surprises fewer actors on the $P D$ than would have been the case for journalist recommendations. That the above expectation is realistic was found and argued for in Sant and Zaman (1996). This leads to our final hypothesis:

Hypothesis III: The impact to analyst recommendations on the publication day, irrespective of its kind, will be lower than recommendations from journalists.

4. See, for example, Healy and Palepu (2001). 


\section{Data Description}

The data consists of buy and sell recommendations of stocks published in six large and well known Swedish newspapers and business magazines for the period 1995-2000, collected from the Mediearkivet and Affärsdata databases. ${ }^{5}$ These sources contain all relevant articles published during the period of interest. Data was extracted from the articles using various search strings with regularly used keywords for stock recommendations, such as: "stock," "buy," "sell," "increase," "decrease," and "recommend." The recommendations were written by either a journalist or an analyst. "Journalist" was defined as a person employed by a newspaper or business magazine to write articles. "Analyst," on the other hand, was defined as a person employed by a bank, brokerage firm, or similar. Each newspaper and business magazine is briefly described here, with more details in appendix, table B.

Affärsvärlden $(A F V)$ is a weekly business magazine whose journalists regularly give stock recommendations. Aftonbladet $(A B)$ is an evening newspaper that publishes recommendations written by both journalists and invited analysts, usually on weekends. Finanstidningen $(F T)$ is a morning business newspaper that publishes recommendations on a daily basis written by their journalists. ${ }^{6}$ Göteborgsposten $(G P)$, a morning newspaper, publishes recommendations by analysts on weekends. Privata Affärer $(P A)$ is a monthly business magazine which publishes recommendations originating from their own journalists. Finally, Veckans Affärer (VA) is a weekly business magazine with their own journalists giving recommendations.

The internal codes of conduct for the newspapers and business magazines (as explained in appendix, table B) are weaker than, for example, the one used by the Financial Times, whose journalists must follow the Code of Practice from the Press Complaints Commission: They must not buy or sell, directly or through agents, shares or securities about which they have written recently or about which they intend to write in the near future; furthermore, they should not speculate by buying or selling shares on a short term basis. For the newspapers

5. See appendix B. Only recommendations of common stocks listed in the A- or O-lists of the Stockholm Stock Exchange were considered; the A-list includes the most traded stocks.

6. During 2002 (after the study period), Finanstidningen, Ekonomi24, and Vision formed a new business newspaper called FinansVision. Both Ekonomi24 and Vision were previously information providers established mainly on the Internet. 
and business magazines in this study, however, journalists were in general allowed to trade in a stock after publication of a buy or sell recommendation, and there were no limits on short-term speculation in stocks not covered by the newspaper or business magazine.

The sample consists of 2282 recommendations, of which 1918 were buy, and 364 sell. $^{7}$ Table 1 shows the number of buy and sell recommendations of each newspaper and business magazine in the sample (displayed in panel A), as well as the totals by journalists and analysts divided into weekday and weekend recommendations (displayed in panel B).

The three smallest newspapers and business magazines are business oriented, and thus may non proportionally attract relatively large actors on the financial markets, whose cumulative actions might be more likely to have an effect on the price of any given stock, because of the size of their individual trades (circulation figures are shown in table B in the appendix). We might consequently expect some newspapers and business magazines to have a larger impact on stock prices than others. The ratio of buy-to-sell recommendations in the sample was roughly 5:1 (table 1). During the study-period, no sell recommendations were found for $G P$ and only two for $P A$. Excluding $G P$ and $P A$, the ratio decreases to approximately $3: 1{ }^{8}$ Journalists gave about 4 times more buy than sell recommendations, whereas analysts gave 13 times more.

The sample was also divided into recommendations being published on weekdays and those published on the weekends (table 1). One of the main explanations to the well documented Monday or weekend effect is that negative news are more frequently released during weekends. The buy-to-sell ratio for recommendations being published during weekdays was $7: 2$, whereas the ratio for weekend publications were $13: 2$, hence sell recommendations were almost twice as common during weekends. It is worth mentioning that no sell recommendations were published on Saturdays.

7. There were occasions when more than one journalist/analyst published the same recommendation in the same newspaper or business magazine on the same day. Those instances were considered as one buy or sell. Contradictory recommendations, however, were disregarded totally.

8. The ratio between buy and sell recommendations found in similar studies are: $3: 1$ in Canes and Lloyd-Davies (1978); 2:1 in Liu et al. (1990); 5:2 in Beneish (1991); 11:2 in Palmon et al. (1994); 8:1 in Sant and Zaman (1996); 1:1 in Ferreira and Smith (1999); and 4:1 in Jordan and Sarkar (2000). The ratio naturally depends on what columns are studied; as some columns mainly focus on buy recommendations. 


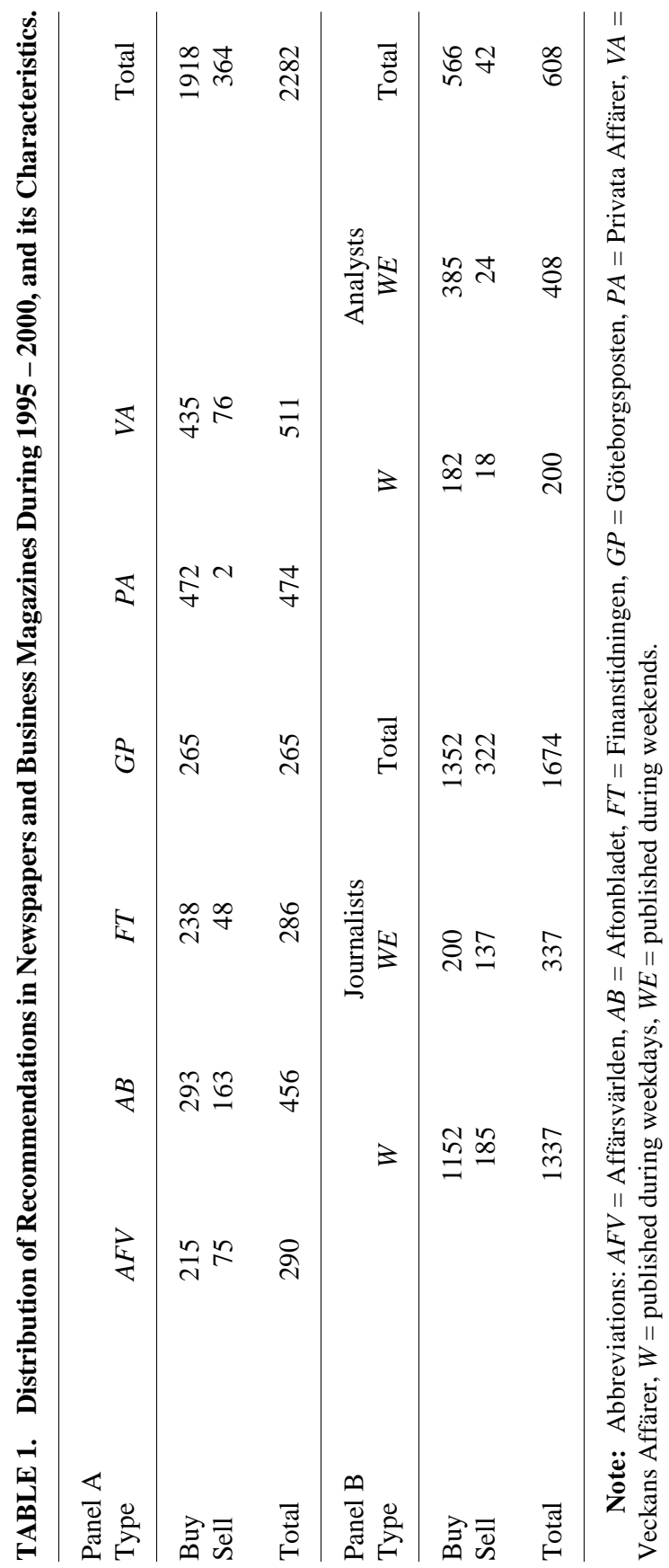


The sample firms had mean and median market capitalizations of Swedish krona (SEK) 55 billion and 4.6 billion on the day of the recommendation. Recommended stocks were thus relatively large compared to the SSE as a whole, for which the mean and median market capitalization in 2000 was SEK 11.6 billion and SEK 0.9 billion. Analysts generally recommended larger firms (mean market capitalization of SEK 70 billion) than did journalists (mean market capitalization of SEK 50 million); both differences from the SSE average are statistically significant. ${ }^{9}$

The daily stock prices came from the Scandinavian Information Exchange (SIX) and were adjusted for dividends being reinvested in the stock on the ex-dividend day. ${ }^{10}$

\section{Research Design}

To analyze the price and volume reactions to recommendations, an event-study method in which the estimation and event windows are separated was used. This design gives estimators that are not influenced by the returns around the event.

Each recommendation was assigned $t=0$ for the $P D .{ }^{11}$ The event window consisted of the 40 days of trading surrounding the $P D$, plus the $P D$ itself, hence $t=-20, \ldots,+20$. The estimation window consisted of 120 days of trading preceding the event window, i.e., $t=-140, \ldots$, $-21 .^{12}$ As discussed in the previous section, recommendations were grouped into different portfolios depending on whether it was a buy or a sell, in which newspaper or business magazine it was published, and whether it originated from a journalist or an analyst.

9. The hypothesis that the means of market values for recommendations from analysts and from journalists were equal can be rejected down to the 3 percent level.

10. SIX provides a software called TRUST, which is a database containing historical stock prices and volumes traded on each day.

11. When a recommendation was published on a day when markets were closed, the next open day was designated as the $P D$.

12. According to MacKinlay (1997), standard practice in an event-study is to set the estimation window to 120 days, thus keeping the intertemporal correlation low and obtaining a large sample. Barber and Loeffler (1993) used a 100 day estimation window and an event window of 51 days. Liu et al. (1990) used a longer estimation window, i.e., 250 days. Others have used longer event windows than estimation windows, for example Liang (1999), where estimation event was 100:150. 


\section{A. Abnormal Return (AR)}

To estimate the abnormal return $(A R)$ for each stock, $i$, on any day, $t$, during the event window, the market model and its standard assumptions were used. The estimated $A R$ for stock $i$ at time $t, A R_{i t}$ during the event period is:

$$
\begin{gathered}
A R_{i t}=R_{i t}-\left(\hat{\alpha}_{i}+\hat{\beta}_{i} R_{m t}\right) \\
t=-20, \ldots,+20 .
\end{gathered}
$$

Because the estimation window consisted of 120 days of trading, approximately 6 months of data was used in the OLS to get estimates $\hat{\alpha}_{i}$ and $\hat{\beta}_{i}$, the coefficients from the market model. As a proxy for the market return, $R_{m}$, the SIX return index (SIXRX) was used. The SIXRX is a value weighted index consisting of all stocks included in the A- and O-lists of SSE (where the A-list contains the most traded stocks), adjusted by reinvesting dividends on ex-dividend dates.

The mean $A R$ for each portfolio, $\overline{A R}$, was calculated from day -20 to +20 , and cumulated from the $P D$ to day +20 in order to obtain the mean cumulative abnormal return, $\overline{C A R}$. In order to test the statistical significance of $\overline{A R}_{t}$ on days $t$ and of $\overline{C A R}_{T_{1}, T_{2}}$ during the interval $T_{1}$ to $T_{2}$, the $A R S$ were standardized. ${ }^{13}$

\section{B. Abnormal Volume (AV)}

In order to establish whether observed reactions are due to price pressure or information content, it was also tested whether abnormal volume in the event window was zero. When testing for abnormal volume $(A V)$ during the event period, the market model for log-transformed trading volume suggested in Ajinkya and Jain (1989) was used. The market model for trading volume can be motivated by assuming a multivariate normal distribution for the cross-section of securities in a manner similar to the motives behind the market model for returns as a statistical model. This method is superior to others for

13. Standardizing the estimated $A R \mathrm{~s}$ for each stock is recommended in Brown and Warner $(1980,1985)$ and later used, for example, by Liu et al. (1990). 
two reasons. First, using log-transformed volume yields a variable that more closely approximates a normal distribution. Second, because the market model brings additional information about the market, it increases the power of tests over the otherwise frequently used mean-adjusted method. In this case, the log-transformed market model for volume can be written as:

$$
\ln \left(1+S K V_{i t}\right)=\alpha_{i}+\beta_{i} \ln \left(1+S K V_{m t}\right)+e_{i t}
$$

where $S K V_{i t}$ is the total Swedish kronor value traded in stock $I$ on day $t ; S K V_{m t}$ is the total $S$ wedish kronor value traded in the market on day $t ; e_{i t}$ is the predicted error for stock $I$ on day $t$; and $\alpha_{i}$ and $\beta_{i}$ are the regression coefficients specific to stock $i$. Ajinkya and Jain (1989) argue that daily trading volumes should be calculated as the total value of trade (Swedish kronor volume) rather than the otherwise frequently used number of shares traded or the fraction of outstanding shares traded.

The $A V$ for stock $i$ on day $t$ is estimated as the prediction error, which is the difference between the actual and the predicted log-transformed trading volume on day $t$, or:

$$
A V_{i t}=v_{i t}-\left(\hat{\alpha}_{i}+\hat{\beta}_{i} v_{m t}\right)
$$

where $v_{i t}$ and $v_{m t}$ are the log-transformed kronor volume for stock $i$ and the market on day $t$ and $\hat{\alpha}_{i}$ and $\hat{\beta}_{i}$ are the OLS estimates of $\alpha_{i}$ and $\beta_{i}$. For a portfolio $N$ stocks, the mean $A V$ for day $t, \overline{A V}_{t}$, is just the averaged $A V$ for all $N$ stocks during day $t$. The test statistic for the mean $A V$ on day $t$ for a sample of $N$ securities, $t_{\overline{A V}}$, is the ratio of the mean excess trading volume to its estimated standard deviation. Mean cumulative abnormal volumes $(C A V \mathrm{~s})$ are also tested for over several windows.

\section{Empirical Results}

\section{A. Abnormal Return (AR)}

The purpose of this study was to analyze price reactions to published stock recommendations, and to discuss whether they generated temporary or permanent price changes. If mean $A R \mathrm{~s}$ and $C A R \mathrm{~s}$ at and 
TABLE 2. Mean Abnormal Return and Mean Cumulative Abnormal Return During 1995 - 2000 for Swedish Buy Recommendations, in Percent.

\begin{tabular}{|c|c|c|c|c|}
\hline \multicolumn{3}{|c|}{ Buy recommendations $(N=1918)$} & \multirow[b]{2}{*}{$\overline{C A R}$} & \multirow[b]{2}{*}{$t$} \\
\hline Day & $A R$ & $t$ & & \\
\hline-20 & $-0.01 \%$ & -0.19 & $-0.01 \%$ & -0.19 \\
\hline-19 & -0.01 & 0.48 & -0.02 & 0.21 \\
\hline-18 & 0.04 & 1.20 & 0.02 & 0.87 \\
\hline-17 & -0.04 & -0.26 & -0.02 & 0.62 \\
\hline-16 & 0.02 & 0.37 & 0.00 & 0.75 \\
\hline-15 & -0.02 & 0.02 & -0.02 & 0.70 \\
\hline-14 & -0.05 & 0.12 & -0.06 & 0.69 \\
\hline-13 & 0.05 & 1.79 & -0.02 & 1.28 \\
\hline-12 & -0.05 & -0.89 & -0.07 & 0.91 \\
\hline-11 & 0.03 & 0.08 & -0.04 & 0.89 \\
\hline-10 & -0.03 & -0.22 & -0.07 & 0.78 \\
\hline-9 & -0.05 & -0.90 & -0.12 & 0.49 \\
\hline-8 & 0.03 & 1.10 & -0.09 & 0.78 \\
\hline-7 & -0.06 & -0.61 & -0.15 & 0.59 \\
\hline-6 & 0.00 & 0.41 & -0.15 & 0.67 \\
\hline-5 & 0.06 & 1.66 & -0.10 & 1.06 \\
\hline-4 & -0.04 & 0.40 & -0.14 & 1.13 \\
\hline-3 & 0.10 & 2.28 & -0.03 & 1.63 \\
\hline-2 & 0.06 & 1.03 & 0.03 & 1.83 \\
\hline-1 & 0.32 & 5.37 & 0.34 & 2.98 \\
\hline$P D$ & 0.79 & 13.49 & 1.13 & 5.86 \\
\hline 1 & 0.19 & 3.35 & 1.32 & 6.53 \\
\hline 2 & -0.10 & -1.30 & 1.22 & 6.02 \\
\hline 3 & 0.00 & 0.76 & 1.22 & 6.05 \\
\hline 4 & -0.11 & -2.11 & 1.11 & 5.50 \\
\hline 5 & -0.12 & -2.10 & 1.00 & 4.99 \\
\hline 6 & -0.04 & -0.69 & 0.96 & 4.76 \\
\hline 7 & 0.11 & 2.16 & 1.07 & 5.08 \\
\hline 8 & -0.07 & -1.30 & 1.00 & 4.75 \\
\hline 9 & -0.03 & -0.15 & 0.97 & 4.64 \\
\hline 10 & -0.04 & -0.25 & 0.93 & 4.52 \\
\hline 11 & 0.02 & 0.62 & 0.95 & 4.56 \\
\hline 12 & -0.04 & 0.42 & 0.91 & 4.57 \\
\hline 13 & -0.11 & -1.15 & 0.80 & 4.30 \\
\hline 14 & 0.04 & 0.46 & 0.84 & 4.32 \\
\hline 15 & 0.05 & 1.47 & 0.89 & 4.50 \\
\hline 16 & -0.15 & -3.13 & 0.74 & 3.93 \\
\hline 17 & -0.05 & -1.22 & 0.69 & 3.68 \\
\hline 18 & -0.06 & -1.40 & 0.63 & 3.41 \\
\hline 19 & -0.13 & -2.29 & 0.50 & 3.00 \\
\hline 20 & 0.05 & 1.07 & 0.55 & 3.13 \\
\hline
\end{tabular}

Note: This portfolio consists of the buy recommendations from table 1 . Time is given in days relative to the $P D$. The mean abnormal and cumulative abnormal returns were estimated as: $\overline{A R}_{t}=\left(\sum_{i=1}^{N} A R_{i t}\right) / N$, and $\overline{C A R}_{T_{1}, T_{2}}=\sum_{t=T_{1}}^{T_{2}} \overline{A R}_{t} \cdot A R_{i t}$ was estimated using estimates from market model regressions for each recommendations $i: A R_{i t}=R_{i t}-\left(\hat{\alpha}_{i}+\hat{\beta}_{i} R_{m t}\right)$. 
immediately after the $P D$ are different from zero, this indicates the desired price reactions. If $C A R \mathrm{~s}$ then tend back toward zero, this indicates that the recommendations revealed no new information making market participants reevaluate stock prices. Observing how $C A R$ s evolve can therefore give us the information needed.

\section{Buy Recommendations}

Table 2 presents the mean daily $A R \mathrm{~s}$, mean $C A R \mathrm{~s}$, and the $t$-statistics for overall buy recommendations. The results indicate that the published recommendations had a significant impact on stock prices, and that they revealed some information that was not already known to all market participants. $^{14}$

Testing the null hypothesis that the daily $A R$ s are equal to zero in the event window, is rejected 4 times out of 41 at the 1 percent level. The mean $A R$ on the $P D$ is 0.79 percent ( $t$-value: 13.49), but this is consistent with an efficient market, since if new and "relevant" information arrives on the financial markets, a price reaction should be expected. On the day prior to the $P D$ it was 0.32 percent ( $t$-value: 5.37 ), and on day $+1,0.19$ percent ( $t$-value: 3.35 ). The statistically significant $A R$ on the day prior to the $P D$ may be due to some market participants already knowing the contents of the article.

The strong positive reaction to buy recommendations on the days before and after the $P D$ is followed by a reversed trend in the mean $A R$ from day 1 to day 20 . The mean $C A R$ for the period was -0.58 percent ( $t$-value:-1.52). Although the reversed trend for these recommendations seems to be due to temporary buying pressure, it seems likely that these recommendations revealed some information. Buy recommendations nevertheless support our Hypothesis 1, meaning that there was no drift different from zero after the $P D$ from which an investor could profit.

\section{Sell Recommendations}

Table 3 presents the mean daily $A R \mathrm{~s}$, mean $C A R \mathrm{~s}$, and the $t$-statistics for sell recommendations. The results indicate that the published recommendations had significant impact on stock prices, and that they

14. Calculations were also done correcting for possible first-order autocorrelation in the residuals of equation (1), and for the standard deviation to allow for residuals being heteroscedastic and contemporaneously correlated across observations. The results were not altered when including these corrections, and they are therefore not presented here. 
TABLE 3. Mean Abnormal Return and Mean Cumulative Abnormal Return During 1995 - 2000 for Swedish Sell Recommendations, in Percent.

\begin{tabular}{|c|c|c|c|c|}
\hline \multicolumn{3}{|c|}{ Sell recommendations $(N=364)$} & \multirow[b]{2}{*}{$\overline{C A R}$} & \multirow[b]{2}{*}{$t$} \\
\hline Day & $A R$ & $t$ & & \\
\hline-20 & $0.07 \%$ & 0.80 & $0.07 \%$ & 0.80 \\
\hline-19 & -0.08 & -0.43 & -0.01 & 0.26 \\
\hline-18 & 0.19 & 1.57 & 0.19 & 1.12 \\
\hline-17 & -0.32 & -1.25 & -0.14 & 0.34 \\
\hline-16 & 0.33 & 1.36 & 0.19 & 0.92 \\
\hline-15 & 0.03 & 0.15 & 0.23 & 0.90 \\
\hline-14 & -0.09 & 0.37 & 0.14 & 0.97 \\
\hline-13 & 0.20 & 1.41 & 0.34 & 1.41 \\
\hline-12 & -0.02 & 0.56 & 0.32 & 1.51 \\
\hline-11 & 0.12 & 1.13 & 0.44 & 1.80 \\
\hline-10 & 0.06 & -0.03 & 0.50 & 1.70 \\
\hline-9 & -0.13 & -0.59 & 0.37 & 1.46 \\
\hline-8 & -0.40 & -1.74 & -0.03 & 0.92 \\
\hline-7 & -0.23 & -2.50 & -0.27 & 0.21 \\
\hline-6 & 0.12 & 1.84 & -0.15 & 0.68 \\
\hline-5 & -0.22 & -1.50 & -0.37 & 0.28 \\
\hline-4 & 0.10 & 0.27 & -0.28 & 0.34 \\
\hline-3 & -0.35 & -2.63 & -0.63 & -0.29 \\
\hline-2 & -0.35 & -1.68 & -0.98 & -0.67 \\
\hline-1 & -0.24 & -0.80 & -1.22 & -0.83 \\
\hline$P D$ & -1.50 & -8.89 & -2.73 & -2.76 \\
\hline 1 & -0.14 & -0.39 & -2.86 & -2.78 \\
\hline 2 & 0.23 & 1.21 & -2.63 & -2.46 \\
\hline 3 & -0.22 & -1.83 & -2.86 & -2.79 \\
\hline 4 & 0.20 & 0.76 & -2.66 & -2.58 \\
\hline 5 & -0.27 & -1.68 & -2.93 & -2.86 \\
\hline 6 & -0.15 & -0.35 & -3.08 & -2.87 \\
\hline 7 & -0.36 & -2.02 & -3.45 & -3.20 \\
\hline 8 & -0.32 & -1.99 & -3.77 & -3.52 \\
\hline 9 & -0.05 & 0.57 & -3.82 & -3.36 \\
\hline 10 & -0.23 & -0.71 & -4.05 & -3.43 \\
\hline 11 & -0.36 & -2.25 & -4.42 & -3.78 \\
\hline 12 & 0.04 & 0.34 & -4.38 & -3.66 \\
\hline 13 & 0.16 & 0.96 & -4.22 & -3.44 \\
\hline 14 & 0.08 & 0.41 & -4.14 & -3.32 \\
\hline 15 & -0.16 & -0.18 & -4.31 & -3.30 \\
\hline 16 & 0.10 & 1.83 & -4.20 & -2.96 \\
\hline 17 & 0.10 & 0.64 & -4.10 & -2.81 \\
\hline 18 & -0.28 & -1.17 & -4.38 & -2.97 \\
\hline 19 & -0.33 & -1.56 & -4.71 & -3.18 \\
\hline 20 & -0.33 & -2.65 & -5.04 & -3.55 \\
\hline
\end{tabular}

Note: This portfolio consists of the sell recommendations from table 1. Time is given in days relative to the $P D$. The mean abnormal and cumulative abnormal returns were estimated using the same equations as those of table 2 . 
revealed new and "relevant" information.

The null hypothesis that the daily $A R$ s are equal to zero can be rejected at the 1 percent level 3 times out of 41 in the event window. Surrounding the $P D$, strong negative price reactions were observed. The $P D$ effect is -1.50 percent ( $t$-value: -8.89 ). The $A R$ on day -3 (before the publication), -0.35 percent, was also significant at the 1 percent level. As before, the effect on the $P D$ could be explained by the contents of the article, and the return observed on day -3 could be due to leakage. Analyzing each and every of the individual sell portfolios (from each newspaper and business magazine) on day -3 shows no unanimous picture, thus the found reaction was not due to leakage. If market participants were already aware of the contents of articles at day -3 , it must have taken three days for the information to be passed on to readers.

The mean CARs indicate that sell recommendations contained information not fully known to market participants prior to publication. At the end of the event window, mean $C A R$ was still significant at the 1 percent level. Furthermore, for the 20 days following the $P D$, it was-2.29 percent ( $t$-value: -2.28 ). Of these 20 days, 13 showed a negative mean. These recommendations therefore revealed new information generating the seemingly permanent price changes, i.e., rejecting Hypothesis 1.

\section{Journalists and Analysts}

Table 4 shows the mean $C A R$ s for the buy recommendations grouped by journalists versus analysts for several windows. The buy recommendations from journalists performed worse during the pre-publication periods (the first one measured from day -20 to -6 , and the second between days -5 and -2 ) than recommendations from analysts did (panel A). During the first pre-recommendation period, the difference in $C A R$ s is negligible. During the second period, however, the difference is substantial, i.e., -1.49 percent (with a z-value of -2.20 ) ${ }^{15}$ The results mean that stocks being buy recommended from journalists performed as well as the market during this period, whereas those from analysts substantially outperformed the market (1.52 percent with a $t$-value of 3.33). Either analysts published buy recommendations of stocks that by pure coincidence performed way better than the market just days before publication, or more probably, they handed the

15. For simplicity, only the univariate tests are considered in the discussion. 
TABLE 4. Mean Cumulative Abnormal Return for Buy and Sell Recommendations, by Journalists versus Analysts, in Percent.

\begin{tabular}{lllll}
\hline Period & $\overline{C A R}$ & $t$ & $\overline{C A R}$ & $t$ \\
\hline
\end{tabular}

Panel A: Buy recommendations

\begin{tabular}{lcrrr} 
& \multicolumn{2}{c}{ Journalists $(N=1352)$} & \multicolumn{2}{c}{ Analysts $(N=566)$} \\
$(-20,-6)$ & -0.28 & -0.02 & 0.16 & 1.26 \\
$(-5,-2)$ & 0.03 & 1.04 & 1.52 & 3.33 \\
$(-1,1)$ & 1.50 & 11.91 & 0.83 & 5.19 \\
$P D$ & 0.97 & 13.59 & 0.37 & 3.83 \\
$(+2,20)$ & -0.99 & -2.67 & -0.27 & -0.16 \\
$(-20,20)$ & 0.26 & 1.72 & 1.24 & 3.10
\end{tabular}

Journalists v.s. Analysts

$\begin{array}{llrrr} & \text { Univariate } & & \text { Multivariate } \\ (-20,-6) & -0.44 & -0.62 & -0.38 & -0.69 \\ (-5,-2) & -1.49 & -2.20 & -0.53 & -1.77 \\ (-1,1) & 0.67 & 1.20 & 0.44 & 1.45 \\ P D & 0.60 & 3.23 & 0.46 & 2.69 \\ (+2,20) & -0.72 & -0.94 & -0.74 & -1.21 \\ (-20,20) & -0.98 & -1.36 & -1.20 & -1.26\end{array}$

Panel B: Sell recommendations

\begin{tabular}{lcccr} 
& \multicolumn{2}{c}{ Journalists $(N=322)$} & \multicolumn{2}{c}{ Analysts $(N=42)$} \\
$(-20,-6)$ & 0.18 & 1.22 & -2.70 & -1.37 \\
$(-5,-2)$ & -1.06 & -3.38 & 0.89 & 1.17 \\
$(-1,1)$ & -2.25 & -6.71 & 0.94 & 1.40 \\
$P D$ & -1.66 & -9.21 & -0.36 & -0.74 \\
$(+2,20)$ & -2.45 & -2.38 & -0.10 & -0.04 \\
$(-20,20)$ & -5.58 & -3.76 & -0.98 & -0.06
\end{tabular}

Journalists v.s. Analysts

\begin{tabular}{llrrr} 
& \multicolumn{3}{c}{ Multivariate } \\
$(-20,-6)$ & Univariate & 0.41 & 2.88 & 0.91 \\
$(-5,-2)$ & 2.52 & -1.82 & -1.94 & -1.20 \\
$(-1,1)$ & -1.95 & -3.10 & -3.19 & -2.68 \\
$P D$ & -3.65 & -2.54 & -1.30 & -1.86 \\
$(+2,20)$ & -1.30 & -1.39 & -2.35 & -1.19 \\
$(-20,20)$ & -2.35 & -2.14 & -4.60 & -1.11 \\
\hline
\end{tabular}

Note: The period for which the cumulative abnormal returns are calculated is displayed in the period-column. The univariate tests of difference in cumulative returns between journalists' and analysts' recommendations were performed using a Wilcoxon ranksum test. The multivariate test was performed running a regression where the dependent variable is the cumulative abnormal return over a certain period, and independent variables were a dummy controlling for which of the two groups the recommendation came (journalist or analyst) and for the size of the recommended stock measured as the log of market capitalization. The figures for the $P D$ are for mean abnormal returns, and not cumulative abnormal returns. 
information to their clients to take advantage of before being published in the newspaper or business magazine. Assuming that analysts possess information they think is unknown to other market participants, then one can also assume that the information will not be immediately passed on to the readers of certain newspapers or business magazines. Instead, we can assume this information to be initially handed to clients who pay large sums of money for "profitable" (and possibly first-hand) information. Journalists, on the other hand, have no such clients to consider before publishing a recommendation. The only consideration he or she might take into account is to profit from the information themselves. This problem is monitored by the editor(s) of the respective newspaper or magazine, as presented in table B of the appendix. Nevertheless, the fact that analyst buy recommendations outperform those from journalists in the second pre recommendation period supports Hypothesis 2. The profitable information in analyst recommendations were thus profited from before published in the newspaper or business magazine.

During the event window (measured from the day prior to the publication to the day after the publication day), there was a 0.67 percent difference in CARs. The market obviously reacts more positively to buy recommendations being from a journalist than if it comes from an analyst. This is displayed even more clearly in the reaction on the publication day. Buy recommendations from journalists has an abnormal return of 0.97 percent (with a $t$-value of 13.59), whereas analysts' buy recommendations has a publication day effect of 0.37 percent (with a $t$-value of 3.83). The difference between the two, 0.60 percent, was found to be statistically significant, i.e., supporting Hypothesis 3. During the short-run post recommendation period (measured from day +2 to +20 ), prices of buy-recommended stocks from both journalists and analysts decreased. This means that the support to Hypothesis 1 from buy recommendations is consistent when dividing the sample into recommendations from journalists and analysts.

Stocks that were sell recommended by journalists increased in price during the first pre-publication period, whereas those from analysts decreased substantially (panel B). Although the difference between the two is substantial, it is far from statistically significant. For the second pre recommendation period, however, sell recommended stocks from journalists decreased and those from analysts increases in price, leaving the difference in $C A R$ s at -1.95 percent (with a $z$-value of -1.82 ). For buy recommendations analysts were found to presumably leaking 
information to their private clients during days -5 to -2 , whereas for sell recommendations they leaked information during days -20 to -6 , again supporting Hypothesis 2. During the event-period, recommendations from journalists decreases in price while those from analysts increases. As was found to be the case for buy recommendations, the sell recommendations from journalists had a significantly larger impact than those from analysts (supporting Hypothesis 3). The difference in abnormal return during the publication day is -1.30 percent (with a $z$-value of -2.54). During the post recommendation period, stocks that were sell recommended by journalists continued to decrease. This means that the results of sell recommendations from journalists reject Hypothesis 1, whereas that from analysts are in favor of the same hypothesis.

When dividing the sample into buy and sell recommendations originating from journalists and analysts, we discover several interesting results. Analysts seem to hand their information to private clients before being published in the newspaper or business magazine. This is done well in advance of the publication, and the profitable information from sell recommendations seems to be taken advantage of sooner than for buy recommendations. This can only be interpreted as sell recommendations being fewer, and therefore more sensitive in their nature than buy recommendations. The results for sell recommendations from analysts should be interpreted with caution, considering the small sample size (42 observations). Another interesting observation is that analysts recommends three times more buy recommendations in relation to sell's than journalists. This is also in line with our expectations that analysts publish the information that serves their own purpose as well as the purpose of their clients. Publishing a buy recommendation may increase trading from investors in that stock for their brokerage house, leading to increased transaction profits. The presented results also indicate that journalist are informative when stocks are down, but they are uninformed when stocks are up. Can we expect journalists to be informed for a certain type of recommendations but not for the other? The information which their buy recommendations are based upon do, to a large extent, originate from analysts. Recommendations are also "lagged" to the "real" event that triggers it, because of time to being published etcetera. Sell recommendations from journalists have a more investigative character, and as such they are surprising to the markets, relatively speaking. In relation to analysts, the journalists and their employers, do not have either the time or resources in discovering 
TABLE 5. Mean Cumulative Abnormal Return for Buy and Sell Recommendations, by Weekdays versus Weekends, in Percent.

\begin{tabular}{lllll}
\hline Period & $\overline{C A R}$ & $t$ & $\overline{C A R}$ & $t$ \\
\hline
\end{tabular}

Panel A: Buy recommendations

\begin{tabular}{lrrrr} 
& \multicolumn{2}{c}{ Weekdays $(N=1334)$} & \multicolumn{2}{c}{ Weekends $(N=584)$} \\
$(-20,-6)$ & -0.17 & 0.53 & -0.12 & 0.42 \\
$(-5,-2)$ & -0.06 & 0.28 & 0.72 & 4.44 \\
$(-1,1)$ & 1.48 & 11.76 & 0.88 & 5.46 \\
$P D$ & 0.95 & 13.30 & 0.44 & 4.35 \\
$(+2,20)$ & -0.66 & -1.61 & -1.05 & -1.77 \\
$(-20,20)$ & 0.60 & 2.49 & 0.43 & 1.91
\end{tabular}

Weekdays v.s. Weekends

\begin{tabular}{lcrrr} 
& Univariate & \multicolumn{3}{c}{ Multivariate } \\
$(-20,-6)$ & -0.05 & -0.12 & 0.10 & 0.19 \\
$(-5,-2)$ & -0.78 & -2.96 & -0.92 & -3.01 \\
$(-1,1)$ & 0.60 & 1.71 & 0.13 & 0.43 \\
$P D$ & 0.51 & 2.61 & 0.21 & 1.21 \\
$(+2,20)$ & 0.39 & 0.52 & 0.41 & 0.65 \\
$(-20,20)$ & 0.16 & 0.36 & -0.27 & -0.27
\end{tabular}

Panel B: Sell recommendations

\begin{tabular}{lrrrr} 
& \multicolumn{2}{c}{ Weekdays $(N=203)$} & \multicolumn{2}{c}{ Weekends $(N=161)$} \\
$(-20,-6)$ & 0.86 & 1.36 & -1.42 & -0.51 \\
$(-5,-2)$ & -0.64 & -2.49 & -1.08 & -1.39 \\
$(-1,1)$ & -2.29 & -5.51 & -1.36 & -2.59 \\
$P D$ & -2.01 & -8.71 & -0.87 & -3.62 \\
$(+2,20)$ & -1.21 & -1.10 & -3.41 & -2.12 \\
$(-20,20)$ & -3.28 & -2.19 & -7.27 & -2.88
\end{tabular}

Weekdays v.s. Weekends

\begin{tabular}{lrrrr} 
& Univariate & \multicolumn{3}{c}{ Multivariate } \\
$(-20,-6)$ & 2.28 & 1.29 & 2.01 & 0.98 \\
$(-5,-2)$ & 0.44 & 1.12 & 0.49 & 0.46 \\
$(-1,1)$ & -0.93 & -1.33 & -0.63 & -0.80 \\
$P D$ & -1.14 & -2.69 & -0.92 & -2.02 \\
$(+2,20)$ & 2.20 & 1.51 & 1.92 & 1.03 \\
$(-20,20)$ & 3.98 & 1.02 & 3.79 & 1.19 \\
\hline
\end{tabular}

Note: The period for which the cumulative abnormal returns are calculated is displayed in the period-column. The univariate tests of difference in cumulative returns between weekday and weekend recommendations were performed using a Wilcoxon ranksum test. The multivariate test was performed running a regression where the dependent variable is the cumulative abnormal return over a certain period, and independent variables where a dummy controlling for during which period of the week the recommendation came (weekday or weekend) and for the size of the recommended stock measured as the log of market capitalization. The figures for the $P D$ are for mean abnormal returns, and not cumulative abnormal returns. 
underpriced stocks. Therefore, we should not be surprised by the found asymmetry in the informational content of these recommendations. Also, analysts seem to be uninformed for both buy and sell recommendations, but pre recommendation CARs showed that this is partly an illusion. In fact, analysts seem to hand their information to clients to take advantage of before being published.

\section{Weekday and Weekend Recommendations}

Table 5 shows the mean $C A R$ s for buy recommendations published during weekdays and weekends for several windows. Stocks that were buy-recommended during weekdays had an unchanged $C A R$ between the days -5 to -2 , whereas recommendations published during weekends had a CAR of 0.72 percent (with a $t$-value of 4.44) (panel A). This implies that there is some lag in buy recommendations being published during weekends in comparison to those published during weekdays. The recommendations during weekends are stocks that have performed relatively well in the last few days. During the event period, weekday recommendations outperformed the weekend recommendations by 0.60 percent (with a $z$-value of 1.71 ). Also the $P D$ effect was significantly larger for weekday recommendations, i.e., 0.51 percent larger (with a $z$-value of 2.61). In the post recommendation period both stocks recommended during weekdays and weekends decreased in price.

The stocks that were sell-recommended during weekends fell during the pre recommendation period (day -20 to day -2 ), whereas those stocks sell recommended during weekdays marginally increased in price (panel B). During the event period, as well as at the publication day, sell-recommended stocks during weekdays decreased more in price than those during weekends. The difference in abnormal return at the publication-day was -1.14 percent (with a $z$-value of -2.69 ). In the post recommendation period, however, the prices of sell-recommended stocks from weekends decrease more than those during weekdays.

The Monday effect means that generally average stock returns are lower on Mondays than during other days. Furthermore, researchers have found individual investors to trade more actively, and institutional investors less actively, on Mondays. The frequency of sell transactions has also been found to be higher on Mondays than during other trading days. What could be expected from these findings here, is for the impact at the $P D$ to buy recommendations published during weekends to be 


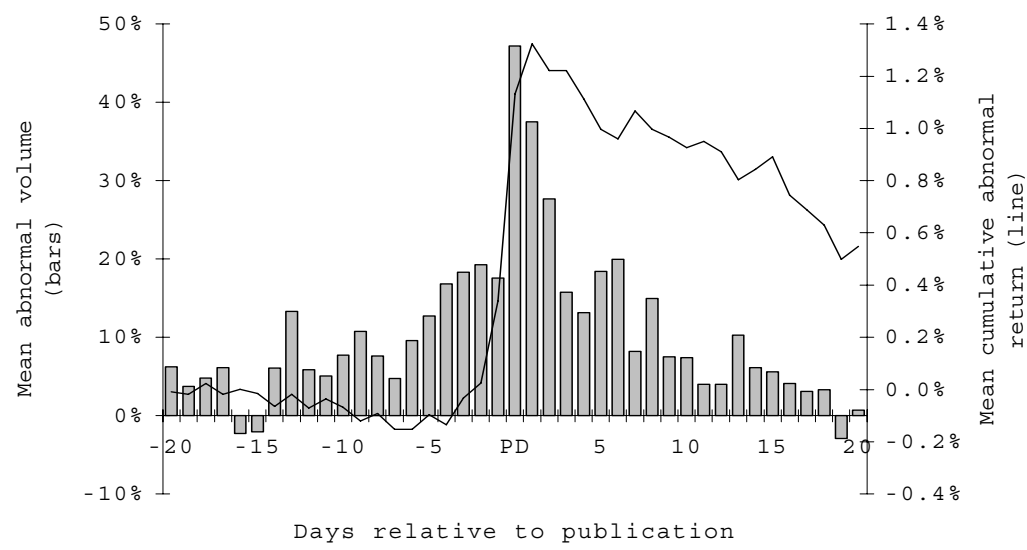

FIGURE 1.-Mean Abnormal Volume and Mean Cumulative Abnormal Return for 1918 Buy Recommendations from Newspapers and Business Magazines.

lower than those published on weekdays, and the impact to sell recommendations published on weekends to be larger. The impact to buy recommendations published on weekends is significantly smaller than weekday recommendations, i.e., as assumed by the Monday effect, whereas sell recommendations on weekends was found to have significantly smaller impact than weekday recommendations, i.e., contradicting the "assumption" from the Monday effect. There is only one reasonable explanation to these findings. From the 161 sell recommendations published on weekends, all but one originates from Aftonbladet, one of the evening tabloids. The impact to these recommendations was much less than for sell recommendations from any other newspaper or business magazine.

The most positive buy recommendations were published during weekdays, and the most negative sell's were published during weekends.

\section{B. Abnormal Volume (AV)}

The daily mean $A V \mathrm{~s}$ for the portfolios consisting of buy and sell recommendations are presented in table 6. Figures 1 and 2 displays the daily mean $A V \mathrm{~s}$ and mean $C A R \mathrm{~s}$ for the buy and sell recommendations. The published stock recommendations also appear to have had 
TABLE 6. Mean Abnormal Volume for Buy and Sell Recommendations

\begin{tabular}{|c|c|c|c|c|}
\hline Day & $A V$ & $t$ & $A V$ & $t$ \\
\hline & \multicolumn{2}{|c|}{ Buy $(N=1918)$} & \multicolumn{2}{|c|}{ Sell $(N=364)$} \\
\hline-20 & $6.22 \%$ & 0.63 & $9.27 \%$ & 0.94 \\
\hline-19 & 3.75 & 0.38 & -1.54 & -0.16 \\
\hline-18 & 4.82 & 0.48 & 15.26 & 1.55 \\
\hline-17 & 6.14 & 0.62 & 4.91 & 0.50 \\
\hline-16 & -2.27 & -0.23 & -3.30 & -0.34 \\
\hline-15 & -2.02 & -0.20 & -3.27 & -0.33 \\
\hline-14 & 6.10 & 0.61 & 0.95 & 0.10 \\
\hline-13 & 13.32 & 1.34 & -0.26 & -0.03 \\
\hline-12 & 5.89 & 0.59 & 4.33 & 0.44 \\
\hline-11 & 5.07 & 0.51 & 0.22 & 0.02 \\
\hline-10 & 7.72 & 0.78 & 8.12 & 0.83 \\
\hline-9 & 10.73 & 1.08 & 15.86 & 1.61 \\
\hline-8 & 7.63 & 0.77 & 14.76 & 1.50 \\
\hline-7 & 4.77 & 0.48 & 6.63 & 0.67 \\
\hline-6 & 9.60 & 0.97 & 5.69 & 0.58 \\
\hline-5 & 12.73 & 1.28 & 3.98 & 0.40 \\
\hline-4 & 16.80 & 1.69 & 12.48 & 1.27 \\
\hline-3 & 18.34 & 1.85 & 25.33 & 2.57 \\
\hline-2 & 19.30 & 1.94 & 17.65 & 1.79 \\
\hline-1 & 17.60 & 1.77 & 10.23 & 1.04 \\
\hline$P D$ & 47.20 & 4.75 & 43.27 & 4.40 \\
\hline 1 & 37.50 & 3.77 & 18.46 & 1.88 \\
\hline 2 & 27.67 & 2.79 & 4.66 & 0.47 \\
\hline 3 & 15.77 & 1.59 & 19.45 & 1.98 \\
\hline 4 & 13.17 & 1.33 & 13.64 & 1.39 \\
\hline 5 & 18.41 & 1.85 & 12.48 & 1.27 \\
\hline 6 & 19.96 & 2.01 & 9.66 & 0.98 \\
\hline 7 & 8.24 & 0.83 & 3.93 & 0.40 \\
\hline 8 & 14.97 & 1.51 & 5.51 & 0.56 \\
\hline 9 & 7.53 & 0.76 & 6.05 & 0.61 \\
\hline 10 & 7.44 & 0.75 & -3.60 & -0.37 \\
\hline 11 & 3.97 & 0.40 & -6.99 & -0.71 \\
\hline 12 & 4.00 & 0.40 & -4.88 & -0.50 \\
\hline 13 & 10.26 & 1.03 & 0.82 & 0.08 \\
\hline 14 & 6.16 & 0.62 & -4.62 & -0.47 \\
\hline 15 & 5.62 & 0.57 & -5.01 & -0.51 \\
\hline 16 & 4.12 & 0.41 & 6.79 & 0.69 \\
\hline 17 & 3.12 & 0.31 & 2.38 & 0.24 \\
\hline 18 & 3.34 & 0.34 & 2.64 & 0.27 \\
\hline 19 & -2.93 & -0.30 & -7.97 & -0.81 \\
\hline 20 & 0.69 & 0.07 & 7.96 & 0.81 \\
\hline
\end{tabular}

Note: Time is given in days relative to the $P D$. Mean abnormal volume was estimated as: $\overline{A V}_{t}=\sum_{i-1}^{N} A V_{i t} / N . A V_{i t}$ was estimated using estimates from market model regressions for each recommendations $i: A V_{i t}=v_{i t}-\hat{\alpha}_{i}-\hat{\beta}_{i} v_{m t}$. 


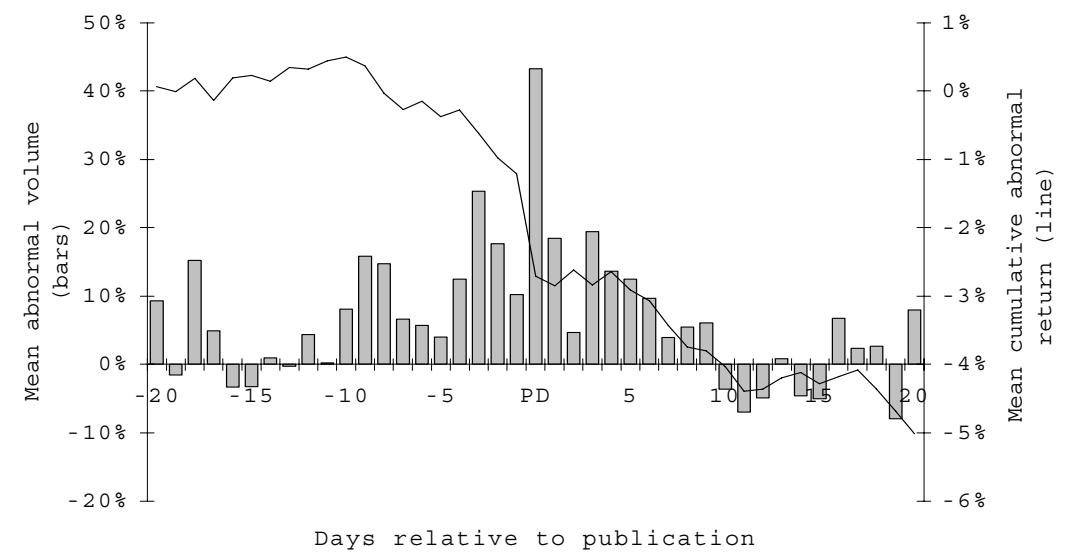

FiguRE 2.- Mean Abnormal Volume and Mean Cumulative Abnormal Return for 364 Sell Recommendations from Newspapers and Business Magazines.

significant impacts on the daily traded volumes in those stocks. ${ }^{16}$

For buy recommendations, the mean $A V$ on the $P D$ was 47 percent and mean $A V \mathrm{~s}$ on the two following days were also substantial and significant at the 1 percent level. ${ }^{17}$ Mean $A V$ s increased especially in the days just before the publication (as did also the mean $A R S$ ) and consequently $C A R$ increased too (figure 1).

For sell recommendations, mean $A V$ on the $P D$ was also large, i.e., 43 percent (with a $t$-value of 4.40). Mean $A V$ s increased just when mean $C A R$ started to decrease (figure 2). At the $P D$, when mean $A V$ peaked (and mean $A R$ was -1.49 percent), $C A R$ fell sharply. As mentioned earlier no reversal is observed for the sell recommendations. Added together, it suggests that published recommendations revealed information, i.e., supporting the information hypothesis.

The mean cumulative abnormal volumes $(C A V \mathrm{~s})$ for the portfolios consisting of buy and sell recommendations from journalists and analysts are shown in table 7.

16. High volumes could be expected near expiration dates for options, something that is not corrected for here. Correcting for possible first-order autocorrelation in the residuals of equation 11 did not change the estimations of the $A V$.

17. When calculating the mean $A V \mathrm{~s}$, numbers were first obtained in logs. If the log was 0.39 , consequently the $A V$ in percentage terms would be $\left(e^{0.39}-1\right) * 100 \%=47 \%$. 
TABLE 7. Mean Cumulative Abnormal Volume for Buy and Sell Recommendations, by Journalists versus Analysts, in Percent.

\begin{tabular}{lllllll}
\hline Period & $\overline{C A V}$ & $t$ & $\overline{C A V}$ & $t$ & $\overline{C A V}$ & $T$ \\
\hline
\end{tabular}

Panel A: Buy recommendations

\begin{tabular}{lcrlrrr} 
& \multicolumn{2}{c}{ Journalists } & \multicolumn{2}{c}{$\begin{array}{c}\text { Analysts } \\
(N=1352)\end{array}$} & \begin{tabular}{c}
\multicolumn{2}{c}{ Journalists } \\
$(N=566)$
\end{tabular} & \multicolumn{2}{c}{ v.s. Analysts } \\
$(-20,-6)$ & $75.3 \%$ & 2.35 & $113.0 \%$ & 2.60 & $-37.7 \%$ & -1.22 \\
$(-5,-2)$ & 61.2 & 4.76 & 81.5 & 5.40 & -20.3 & -0.58 \\
$(-1,1)$ & 110.3 & 10.56 & 78.3 & 6.93 & 32.0 & 1.25 \\
$(\mathrm{PD})$ & 53.8 & 4.31 & 32.5 & 4.30 & 21.3 & 1.06 \\
$(2,20)$ & 148.0 & 3.23 & 212.7 & 3.69 & -64.7 & -1.80 \\
$(-20,20)$ & 383.7 & 4.65 & 480.4 & 4.55 & -96.7 & -1.89
\end{tabular}

Panel B: Sell recommendations

\begin{tabular}{lllcrrr} 
& \multicolumn{2}{c}{$\begin{array}{l}\text { Journalists } \\
(N=322)\end{array}$} & $\begin{array}{c}\text { Analysts } \\
(N=42)\end{array}$ & \multicolumn{3}{c}{ Journalists } \\
$(-20,-6)$ & $60.7 \%$ & 0.85 & $186.9 \%$ & 0.88 & $-126.2 \%$ & -0.35 \\
$(-5,-2)$ & 58.9 & 1.86 & 54.8 & 0.85 & 4.1 & -0.16 \\
$(-1,1)$ & 74.9 & 3.12 & 31.5 & 0.35 & 43.4 & -0.14 \\
$(\mathrm{PD})$ & 45.6 & 3.80 & 26.3 & 1.08 & 19.3 & 0.53 \\
$(2,20)$ & 48.3 & 0.44 & 133.2 & 0.42 & -84.9 & 0.54 \\
$(-20,20)$ & 235.6 & 1.16 & 405.0 & 0.78 & -169.4 & 0.05 \\
\hline
\end{tabular}

Note: The period for which the cumulative abnormal returns are calculated is displayed in the period-column. The univariate tests of difference in cumulative returns between journalists' and analysts' recommendations were performed using a Wilcoxon ranksum test. The figures for the $P D$ are for mean abnormal volumes.

When volumes are cumulated over different windows (the same windows as in subsection IV A), we see that the recommendations generates higher-than normal trading volumes at the publication day for both buy and sell recommendations and from both journalists and analysts. Buy recommendations from both journalists and analysts were followed by higher trading volumes in the next couple of weeks after the publication day. The most interesting aspect of table 7 is the difference in mean $C A V \mathrm{~s}$ between journalist and analyst recommendations over these windows. If we focus on the window for the whole event period, i.e., days -20 to +20 , the trading volume in analyst recommended stocks is much higher than in journalist recommended stocks. This is true for both buy (panel A) and sell recommendations (panel B).

In subsection IV A, we were able to show that the information in analyst buy recommendations were presumably profited from during days -5 to -2 , and analyst sell recommendations were profited from during days -20 to -6 . For buy recommendations, days -5 to -2 had a 
20 percent higher mean $C A V$ for analyst recommendations than journalist recommendations. During the event prior to that (e.g., days -20 to -6 ), mean $C A V$ was about 38 percent higher for analyst recommendations. Furthermore, journalist recommendations had higher mean $C A V$ surrounding the publication day (days -1 to +1 ), but before and after that period, analyst-recommended stocks gave rise to larger mean $C A V$ s. Sell recommendations from analysts gave rise to a 187 percent larger mean $C A V$ for the period when analyst clients presumably take profit from the information in the recommendations published.

The same pattern observed for buy recommendations was found for sell recommendations as well, namely that before and after the period just surrounding the publication day, analyst recommended sell recommendations gave rise to much higher trading volumes. That mean $C A V$ s are higher during the periods when analysts or their clients are assumed to take advantage of the information that will later be published in the recommendations confirms previous expectations, namely that there exist a difference in recommendation behavior between journalists and analysts. That stocks being recommended by journalists have higher mean $C A V \mathrm{~s}$ in the period surrounding the publication day could be expected since they generally report on recently released information related to that stock.

\section{Bid/Ask Spread}

Examining the bid/ask spread for published recommendations have been proposed in Glosten and Milgrom (1985) as important in distinguishing the information hypothesis from the price-pressure hypothesis. It is argued that a market maker will widen the spread when facing informed traders to recoup losses from informational disadvantages, and decreasing the spread when facing uninformed traders. Therefore, a lowered spread is considered as supporting the $P P H$ since naive investors are trying to profit from the recommendations, and an increased spread is considered as supporting the $I H$ since the market maker then faces informed investors. The relative bid/ask spread was first calculated for each individual recommendation as the ratio of ask price less bid price divided by the midpoint of bid and ask prices and then averaged over all stocks for the same type. This approach was previously used in Liang (1999). The bid/ask spread for buy and sell recommendations are presented in table 8 .

Stocks that were given a buy recommendation experienced a lowered 
TABLE 8. Bid/Ask Spreads in Percentage to Buy and Sell Recommendations.

\begin{tabular}{lcccccc}
\hline & \multicolumn{3}{c}{ Buy recommendations } & \multicolumn{3}{c}{ Sell recommendations } \\
Day & All & J's & A's & All & J's & A's \\
\hline \multirow{2}{*}{1} & $1.086 \%$ & $1.144 \%$ & $0.948 \%$ & $1.483 \%$ & $1.479 \%$ & $1.517 \%$ \\
PD & 1.054 & 1.118 & 0.901 & 1.539 & 1.501 & 1.833 \\
& $(1.92)$ & $(1.20)$ & $(1.94)$ & $(-0.65)$ & $(-0.24)$ & $(-1.28)$ \\
1 & 1.046 & 1.139 & 0.823 & 1.394 & 1.398 & 1.367 \\
& $(0.20)$ & $(-0.69)$ & $(1.19)$ & $(1.67)$ & $(1.09)$ & $(2.28)$ \\
\hline
\end{tabular}

Note: The bid/ask was calculated as the difference in ask and bid price divided by the midpoint between the two. Considered prices are the closing prices each day. $t$-stats are reported in parentheses, where for example the $t$-stats below the spread for the publication day tests the hypothesis that spreads are equal between day -1 and the publication day.

bid/ask spread on the $P D$ relative to the previous day, hence market makers faced uninformed traders who try to profit from these recommendations. Sell recommendations experienced an increased spread on the $P D$. The increase was marginal, but implies that market makers faced informed traders. The sell recommendations giving the largest increase in bid/ask spread when published were those originating from analysts. Following the $P D$, sell recommended stocks experienced a decreased spread, possibly because of the reduced informational asymmetry the publications gave rise to. Results indicate that buy recommendations support the $P P H$, whereas sell recommendations support the $I H$, which is in line with previous presented results.

\section{Post-Publication Drift}

Whether the observed stock-price reactions to published recommendations were due to price pressure or information content can be further supported by analyzing the post publication drift. The post publication drift for buy recommendations are displayed in figure 3 and the drift for sell recommendations are displayed in figure 4.

Studying figure 3 it is obvious that the ARS observed for all buy recommendations did not last for long. Investors seemingly overreacted to the information contained in the recommendations. In fact, the stock-price reaction following buy recommendations was rather small and trivial. Buy recommendations originating from journalists and analysts showed similar pictures. Buy recommendations, irrespective of its origin, gave rise to a positive and statistically significant $P D$ effect, 


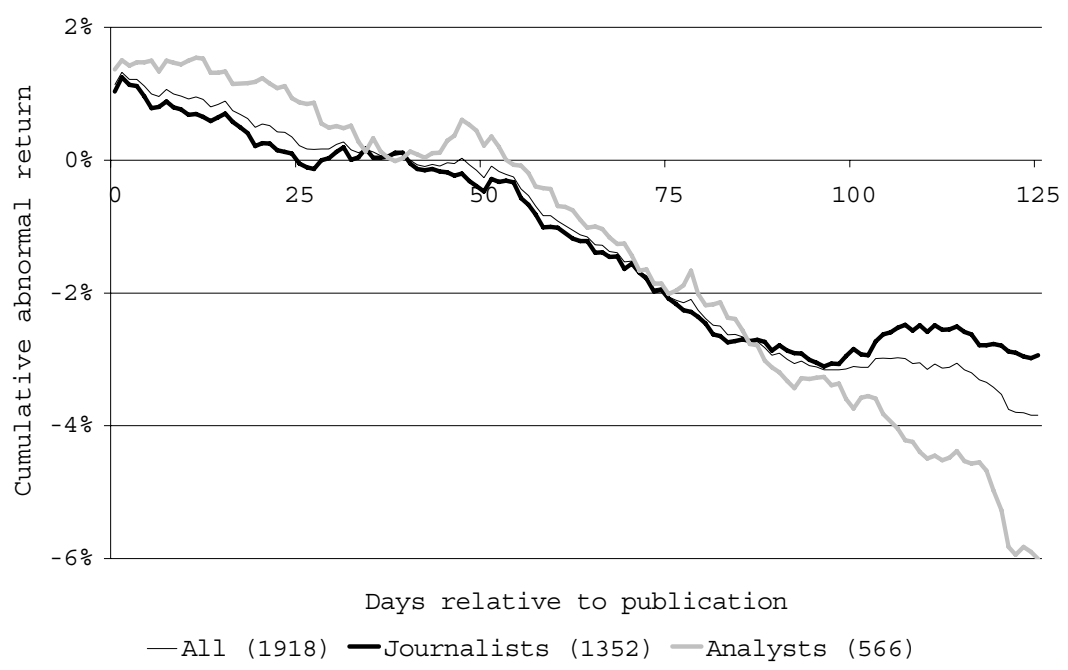

Figure 3.-Post Publication Drift in Securities Prices for BuyRecommended Stocks. Parentheses include the number of recommendations from the respective group. Abnormal returns are calculated using betas and alphas estimated during a 120-day estimation period from day -140 to day -21 . Cumulative abnormal returns are calculated from day -20 to day 125 , but displayed from the day of publication.

a result of buying pressure caused by investors trying to profit from these recommendations. Following the $P D$ effect, there was a mean-return reversal erasing that effect and more. Following these buy recommendations for 125 days (approximately six months), an investor would have lost 3.8 percent.

The negative $P D$ effect that was earlier observed for sell recommendations was followed by further decreasing stock prices. An investor acting on these recommendations would have earned 11.0 percent over the following six months. The $P D$ effect was permanent and it is clear that sell recommendation support the information hypothesis. When these recommendations were divided into those from journalists and analysts, we can see that analyst recommendations initially displayed a negative drift. After about 40 days, however, the sell recommended stocks experienced increasing stock prices. While journalists sell recommendations contain information of real value, leading to a permanent change in securities prices, analysts' 


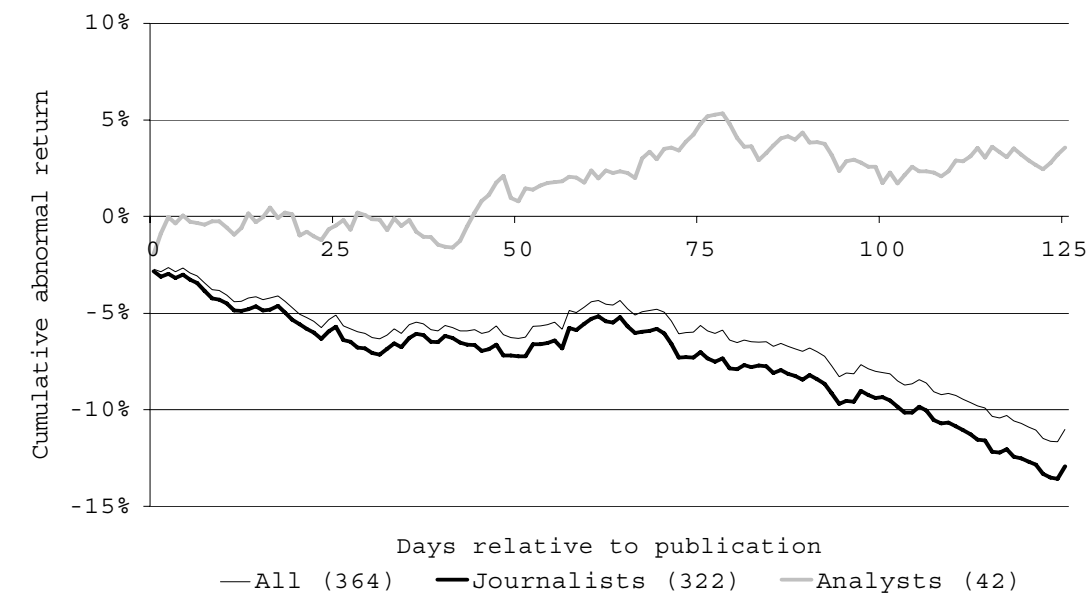

FIGURE 4.-Post Publication Drift in Securities Prices for Sell

Recommended Stocks. Figures in parenthesis indicate the number of recommendations from the respective group. Abnormal returns are calculated using betas and alphas estimated during a 120-day estimation period from day -140 to day -21 . Cumulative abnormal returns are calculated from day -20 to day 125 , but displayed from the day of publication.

recommendations did not. The only reasonable explanation is the small sample size of these recommendations.

\section{Summary and Conclusions}

This paper examined the stock-price reaction to buy and sell recommendations for common stocks published in Swedish newspapers and business magazines during the period 1995 - 2000. In order to clarify whether the found $P D$ stock price reactions were due to either price pressure or the informational content, trading volumes on and about the $P D$, bid/ask spreads, and post publication drifts were analyzed.

The results favor the price-pressure hypothesis (i.e., in support of our Hypothesis 1) for buy recommendations. The statistically significant $P D$ effect for these recommendations, as well as the following mean return reversal is evidence of price pressure. This is also supported by 
the found larger than normal trading volumes at and about the $P D$, decreasing bid/ask spread, and the negative post publication drift in securities prices. For sell recommendations the results support the information hypothesis (i.e., rejecting our Hypothesis 1). These recommendations experienced a statistically significant negative $P D$ effect, followed by further falling stock prices instead of reverting. Again larger than normal trading volumes were observed, but for these recommendations, the bid/ask spread increased on the $P D$ (although statistically insignificant). The observed $P D$ effect for these recommendations gives rise to a permanent change due to the fundamental revaluation of the stocks from market participants.

The observed $P D$ effect for all buy recommendations ( 0.79 percent) is relatively small compared to the referenced studies. In this paper, all buy and sell recommendations published in newspapers and business magazines were used, in comparison to some studies where no reiterations were accepted. The $P D$ for sell recommendations $(-1.50$ percent) is relatively large. Because of its relative rarity, the reaction to sell recommendations is large, and as shown, gives rise to permanent price changes.

Separating the recommendations into those originating from journalists and from analysts and analyzing the results over certain windows, it was found that the impact on stock prices from analysts' recommendations was lower than that of journalists. That is, our Hypothesis 3 is supported in full. Buy recommendations from both analysts and journalists resulted in significant $P D$ effects, followed by reversion erasing almost all the ARS. On the other hand, sell recommendations from journalists contained new information whereas those of analysts did not. Overall the results are in favor of Hypothesis 1 , but the results from sell recommendations by journalists reject the hypothesis since these recommendations could be used to make profits after the $P D$. Our expectations prior to generating and analyzing the results were that it could not be profitable to invest according to the recommendations and earn abnormal returns. The only deviation registered to that expectation was the sell recommendations from journalists which turned out to be profitable to follow. Investing according to those recommendations involves taking short positions in recommended stocks, which may not always be possible. The outcome of such a limitation may be that the profitability from following these 
recommendations disappears altogether.

Information contained in analysts recommendations were leaked earlier, both for buy and sell recommendations, which supports Hypothesis 2. Furthermore, information in sell recommendations were leaked before that in buy recommendations. The first is explained by the very job nature of analysts and that they hand the information to their private clients to profit from before being published. The second can only be explained by sell recommendations being seen as more sensitive and consequently taken advantage of earlier. That journalists are informative when stocks are down, but they are not when markets are up, can be explained in buy recommendations simply being "market reports" and therefore not surprising the market, whereas sell recommendations, which have a more investigative flavor, does.

Evidence shows that the most positive buy recommendations were published during weekdays, whereas the most negative sell recommendations were published during the weekend. Positive information seems to be released as they surface, whereas there seems to be a lag in publication of negative information. Just as the well documented Monday effect assumes, the impact to buy recommendations published during the weekend is smaller than for those published during the weekdays. The Monday effect would also assume the impact to sell recommendations being published on weekends to be larger than during weekdays. However, the results found here showed to be the other way around, which can only be explained by these recommendations originating from one and only source (Aftonbladet).

The mean $A V \mathrm{~s}$ observed before the $P D$ also suggest that the information published was already known to at least some market participants. This raises a serious question to the editors of the newspapers and business magazines. Since analysts' recommendations appear to contain no new information (at least to the public by the time they are published), why then are their recommendations published in the first place?

The observed difference in quality between buy and sell recommendations suggests that less effort was put into buy recommendations, and in fact the sample had a five-to-one ratio of buy to sell recommendations, which this finding might account for. Newspapers and business magazines may thus focus more on quantity than on quality - just because it is easier. 


\section{Appendix}

\section{A. Results from previous research}

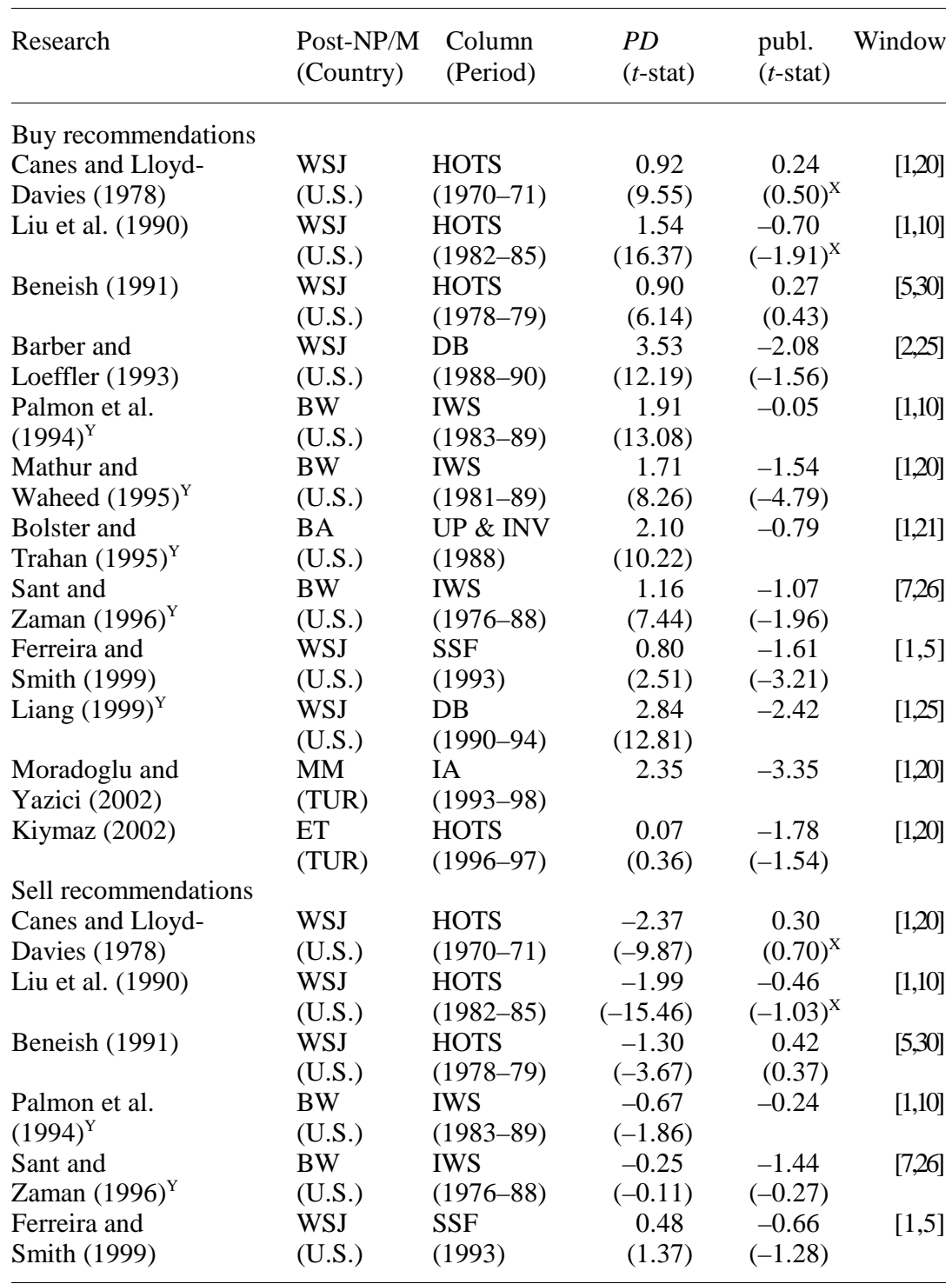

Note: Abbreviations: $\mathrm{NP} / \mathrm{M}=$ Newspaper/Magazine; $P D=$ Publication day; $\mathrm{WSJ}=$ Wall Street Journal; BW = Business Week; BA = Barron's; UP = Up and Down Wall Street; INV $=$ Investment News and Views; MM = Moneymatik; ET = Ekonomik Trend; HOTS = Heard on the street; DB = Dartboard; SSF $=$ Small Stock Focus; IWS = Inside Wall Street; and IA $=$ Investor-Ali. ${ }^{\mathrm{X}}=$ Author's own calculations. ${ }^{\mathrm{Y}}=z$-statistics instead of $t$-statistics. 
B. Description of newspapers and magazines

\begin{tabular}{|c|c|c|c|c|c|}
\hline Source & Type & Circulation & Who & $\begin{array}{l}\text { May own } \\
\text { stocks }\end{array}$ & Restrictions \\
\hline AFV & $\mathrm{BM}$ & 27,600 & $\mathrm{~J}$ & Yes & $\begin{array}{l}\text { Must inform the management } \\
\text { board of holdings. May not } \\
\text { trade in recommended stocks } \\
\text { before publication. If a profit is } \\
\text { made, recommended and } \\
\text { bought stocks must be held at } \\
\text { least } 3 \text { months. }\end{array}$ \\
\hline $\mathrm{AB}$ & EN & 117,00 & $\mathrm{~J} / \mathrm{A}$ & & \\
\hline FT & $\mathrm{BD}$ & 38,300 & $\mathrm{~J}$ & Yes & $\begin{array}{l}\text { All trades must be reported to } \\
\text { the chief editor. Recommended } \\
\text { and bought stocks must be held } \\
\text { at least } 3 \text { months. }\end{array}$ \\
\hline GP & $\mathrm{MN}$ & 380,600 & A & Yes & $\begin{array}{l}\text { Information found in } \\
\text { employees' work should not be } \\
\text { used to make profits on stocks. }\end{array}$ \\
\hline PA & $\mathrm{BM}$ & 27,400 & $\mathrm{~J} / \mathrm{A}$ & Yes & $\begin{array}{l}\text { May not trade in recommended } \\
\text { stocks before publication. } \\
\text { Relatives are included. May not } \\
\text { write recommendations or } \\
\text { analytic articles where they } \\
\text { have a personal interest. }\end{array}$ \\
\hline VA & BW & 288,500 & $\mathrm{~J} / \mathrm{A}$ & Yes & $\begin{array}{l}\text { May not trade in recommended } \\
\text { stocks before publication. }\end{array}$ \\
\hline
\end{tabular}

Note: This table shows the type of each newspaper and business magazine sampled, who wrote the stock recommendations (a journalist or an analyst), whether or not the journalist/analyst was allowed to own stocks, and any restrictions they must follow. Abbreviations: $\mathrm{J}=$ Journalist; $\mathrm{A}=$ Analyst; $\mathrm{BW}=$ Business Weekly; EN $=$ Evening newspaper; $\mathrm{BD}=$ Business daily; $\mathrm{MN}=$ Morning newspaper; $\mathrm{BM}=$ Business monthly. Source (circulation): TS AB.

\section{References}

Ajinkya, B. B., and Jain, P.C. 1989. The behavior of daily stock market trading volume. Journal of Accounting and Economics 11:331-359.

Barber, B. M., and Loeffler, D. 1993. The dartboard column: Second-Hand information and price pressure. Journal of Financial and Quantitative Analysis 28(2):273-284.

Beneish, M. B. 1991. Stock prices and the dissemination of analysts' recommendations. Journal of Business 64(3):393-416.

Bolster, P. J., and Trahan, E. A. 1995. The Impact of Barron's recommendations on stock prices. Quarterly Journal of Business and 
Economics 34(4):3-15.

Brown, S. J., and Warner, J. B. 1980. Measuring Security price performance. Journal of Financial Economics 8(3):205-258.

Brown, S. J., and Warner, J. B. 1985. Using daily stock returns: The case of event studies. Journal of Financial Economics 14(1):3-31.

Canes, M., and Lloyd-Davies, P. 1978. Stock Prices and the Publication of Second-Hand Information. Journal of Business 51(1):43-56.

Ferreira, E. J, and Smith, S. D. 1999. Stock price reactions to recommendations in the Wall Street Journal "Small Stock Focus" column. Quarterly Review of Economics and Finance 39:379-389.

Glosten, L. R., and Milgrom, R. 1985. Bid, ask and transaction prices in a specialist market with heterogeneously informed traders. Journal of Financial Economics 14:71-100.

Healy, P. M., and Palepu, K. G. 2001. Information asymmetry, corporate disclosure and the capital markets: A review of the empirical disclosure literature. Journal of Accounting and Economics 31:405-440.

Jegadeesh, N, and Kim, W. 2003. Value of analyst recommendations: International evidence. Working Paper, Emory University, and University of Illinois at Urbana-Capnaign, May.

Jordan, D. J., and Sarkar, S. K. 2000. Stock price reactions to regional wall street journal securities recommendations. Quarterly Journal of Business and Economics 39:50-61.

Kiymaz, H. 2002. The stock market rumors and stock prices: A Test of pricepressure and size effects in an emerging market. Applied Financial Economics 12(7):469-475.

Liang, B. 1999. Price pressure: Evidence from the "Dartboard" column. Journal of Business 71(1):119-134.

Liu, P.; Smith, S. D.; Syed, A. A. 1990. Stock price reactions to the Wall Street Journal's securities recommendations. Journal of Financial and Quantitative Analysis 25(3):399-410.

MacKinlay, C. A. 1997. Event studies in economics and finance. Journal of Economic Literature 35(1):13-39.

Mathur, I., and Waheed, A. 1995. Stock price reactions to securities recommendations in Business Week's "Inside Wall Street". Financial Review 30(3):583-604.

Muradoglu, G., and Yazici, B. 2002. Dissemination of Stock recommendations and small investors: Who benefits? Multinational Finance Journal 6(1):29-42.

Palmon, O.; Sun, H.-L.; Tang, A. P. 1994. The impact of publication of analysts' recommendations on returns and trading volume. Financial Review 29(3):395-417.

Sant, R., and Zaman, M. A. 1996. Market reactions to Business Week's “Inside Wall Street" column: A self-fulfilling prophecy. Journal of Banking and Finance 20:617-643. 